\title{
Domestication of Campylobacter jejuni NCTC 11168
}

\author{
Ben Pascoe ${ }^{1,2}$ †, Lisa K. Williams ${ }^{3}$, Jessica K. Calland ${ }^{1}$, Guillaume Meric ${ }^{1,4,5}$, Matthew D. Hitchings ${ }^{3}$, Myles Dyer ${ }^{3}$, \\ Joseph Ryder 1 , Sophie Shaw ${ }^{6}$, Bruno S. Lopes ${ }^{6}$, Cosmin Chintoan-Uta7 , Elaine Allan ${ }^{8}$, Ana Vidal ${ }^{9} \neq$, Catherine Fearnley , \\ Paul Everest ${ }^{10}$, Justin A. Pachebat ${ }^{11}$, Tristan A. Cogan ${ }^{12}$, Mark P. Stevens ${ }^{7}$, Thomas J. Humphrey ${ }^{3}$, Thomas S. Wilkinson ${ }^{3}$, \\ Alison J. Cody ${ }^{13}$, Frances M. Colles ${ }^{13}$, Keith A. Jolley ${ }^{13}$, Martin C. J. Maiden ${ }^{13,14}$, Norval Strachan' ${ }^{6}$, Bruce M. Pearson ${ }^{15}$, \\ Dennis Linton ${ }^{16}$, Brendan W. Wren ${ }^{15,17}$, Julian Parkhill ${ }^{18}$, David J. Kelly ${ }^{19}$, Arnoud H. M. van Vliet ${ }^{20}$, Ken J. Forbes ${ }^{6}$ and \\ Samuel K. Sheppard ${ }^{1,2,3,13, *}$
}

\begin{abstract}
Reference and type strains of well-known bacteria have been a cornerstone of microbiology research for decades. The sharing of well-characterized isolates among laboratories has run in parallel with research efforts and enhanced the reproducibility of experiments, leading to a wealth of knowledge about trait variation in different species and the underlying genetics. Campylobacter jejuni strain NCTC 11168, deposited at the National Collection of Type Cultures in 1977, has been adopted widely as a reference strain by researchers worldwide and was the first Campylobacter for which the complete genome was published (in 2000). In this study, we collected 23 C. jejuni NCTC 11168 reference isolates from laboratories across the UK and compared variation in simple laboratory phenotypes with genetic variation in sequenced genomes. Putatively identical isolates, identified previously to have aberrant phenotypes, varied by up to 281 SNPs (in 15 genes) compared to the most recent reference strain. Isolates also display considerable phenotype variation in motility, morphology, growth at $37^{\circ} \mathrm{C}$, invasion of chicken and human cell lines, and susceptibility to ampicillin. This study provides evidence of ongoing evolutionary change among $C$. jejuni isolates as they are cultured in different laboratories and highlights the need for careful consideration of genetic variation within laboratory reference strains. This article contains data hosted by Microreact.
\end{abstract}

\section{DATA SUMMARY}

Short read data are archived on the NCBI SRA associated with BioProject accession PRJNA517467 (https://www.ncbi.nlm. nih.gov/bioproject/PRJNA517467).

Long read data are archived on the ENA associated with BioProject accession PRJEB33069 (https://www.ebi.ac.uk/ ena/data/search?query=PRJEB33069).

Received 16 April 2019; Accepted 03 June 2019; Published 16 July 2019

Author affiliations: ${ }^{1}$ The Milner Centre for Evolution, University of Bath, Claverton Down, Bath, UK; ${ }^{2}$ MRC CLIMB Consortium, Bath, UK; ${ }^{3}$ Swansea University Medical School, Swansea University, Singleton Park, Swansea, UK; ${ }^{4}$ Cambridge Baker Systems Genomics Initiative, Baker Heart and Diabetes Institute, 75 Commercial Rd, Melbourne 3004, Victoria, Australia; ${ }^{5}$ Department of Infectious Diseases, Central Clinical School, Monash University, Melbourne, Victoria 3004, Australia; ${ }^{6}$ University of Aberdeen, Aberdeen, UK; ${ }^{7}$ Roslin Institute, Edinburgh, UK; ${ }^{8}$ UCL Eastman Dental Institute, University College of London, London, UK; ${ }^{9}$ Animal and Plant Health Agency, Weybridge, Surrey, UK; ${ }^{10}$ University of Glasgow, Glasgow, UK; ${ }^{11}$ University of Aberystwyth, Aberystwyth, UK; ${ }^{12}$ School of Clinical Veterinary Science, Langford, Bristol, UK; ${ }^{13}$ Department of Zoology, University of Oxford, Oxford, UK; ${ }^{14} \mathrm{NIHR}$ Health Protections Research Unit in Gastrointestinal Infections, University of Oxford, Oxford, UK; ${ }^{15}$ Quadram Institute Bioscience, Norwich, UK; ${ }^{16}$ University of Manchester, Manchester, UK; ${ }^{17}$ London School of Hygiene and Tropical Medicine, London, UK; ${ }^{18}$ Wellcome Sanger Institute, Wellcome Genome Campus, Hinxton, Cambridge, UK; ${ }^{19}$ Department of Molecular Biology and Biotechnology, The University of Sheffield, Sheffield, UK; ${ }^{20}$ School of Veterinary Medicine, University of Surrey, Surrey, UK.

*Correspondence: Samuel K. Sheppard, s.k.sheppard@bath.ac.uk

Keywords: Campylobacter; genomics; microbial evolution; culture collections.

Abbreviations: CDS, coding sequence; $r / m$, ratio at which recombination introduces nucleotide changes relative to mutation.

$\ddagger$ Present address: Antimicrobial Resistance Policy and Surveillance Team, Veterinary Medicines Directorate, Department for Environment, Food and Rural Affairs (Defra), Surrey, UK.

†These authors contributed equally to this work

Data statement: All supporting data, code and protocols have been provided within the article or through supplementary data files. Two supplementary tables are available with the online version of this article.

000279 @ 2019 The Authors

This is an open-access article distributed under the terms of the Creative Commons Attribution License, which permits unrestricted use, distribution, and reproduction in any medium, provided the original work is properly cited. 
All assembled genomes are also available on figshare (doi: $10.6084 / \mathrm{m} 9$. figshare.7849268). Phylogeny is visualized on microreact: https://microreact.org/project/NCTC11168.

\section{INTRODUCTION}

The sharing of bacterial reference or type strains among laboratories is a fundamental part of microbiology. This informal and often uncelebrated enterprise has supported academic, health, food and veterinary research worldwide, underpinning microbiology innovation. The history of the exchange and classification of bacterial type strains has incorporated the work of some of the most influential microbiologists [1]. One such strain belongs to the important food-borne pathogen species Campylobacter jejuni.

For C. jejuni, the publication of a simplified culturing technique and deposition of a reference isolate at the National Collection of Type Cultures (NCTC 11168) in 1977 (by Martin Skirrow) marked the end of the first century of research into this organism [2]. The first description of an organism likely to be Campylobacter was made in Naples in 1884. Theodor Escherich observed spiral bacteria in stool specimens from patients with diarrhoeal disease but he was unable to culture them [3,4]. Successful isolation of Bacterium coli commune (now Escherichia coli) from his young dysenteric patients helped pioneer bacterial genetics and lay the foundations of modern microbiology $[1,5]$. However, throughout his career, Escherich continued to identify 'spirilla' in cases of cholera-like and dysenteric disease. It is likely that the microorganisms he described were Campylobacter with their typical spiral morphology and association with enteritis $[4,6]$.

Early in the 20th century researchers investigating veterinary cases of fetal abortion and winter dysentery in cattle [7] described several species that would later become part of the genus Campylobacter, including Vibrio jejuni [8], V.fetus [9], V. fetus venerealis and $V$. fetus intestinalis [10]. Isolation techniques that permitted the growth of Campylobacter from human faeces drew attention to its importance as a human pathogen [11-13]. The genus name Campylobacter (meaning curved rod) was proposed by Sebald and Véron in 1963 and subsequently verified in 1973 with the broader acceptance of Campylobacter species as human pathogens $[14,15]$. Skirrow's more convenient culturing technique and the availability of a model reference strain sparked renewed interest in Campylobacter research later in the 20th century $[16,17]$. Model strains allowed for comparison of experiments within laboratories and isolates were passed among laboratories across the world [18-23]. When the $C$. jejuni NCTC 11168 genome was sequenced in 2000 [24] this type strain was cemented as an important reference strain for Campylobacter research. Additional detail was added to the $C$. jejuni genome following its re-annotation (accession: AL11168.1), including revised coding sequence (CDS) identification incorporating potential for phase variation [25-29].

\section{Impact Statement}

In this paper, we comment on the changing role of laboratory reference strains. While the model organism allows basic comparison within and among laboratories, it is important to remember the effect even small differences in isolate genomes can have on the validity and reproducibility of experimental work. We quantify differences in 23 reference Campylobacter genomes and compare them with observable differences in common laboratory phenotypes.

Today, many aspects of the biology of this organism are well characterized. Identification of genomic regions primed for post-translational modification, in particular decoration of surface proteins with glycans [30], pseudaminic acid [31-33] and legionaminic acid [34], have improved understanding of the mechanisms of ganglioside mimicry [35], epithelial cell invasion, host immune-evasion, colonization [36, 37] and development of neurological sequelae such as GuillainBarré syndrome [38]. Furthermore, insights into virulence traits including strategies to sequester the iron required for infection were detailed using NCTC 11168 [39-41]. Vaccine targets have been identified [42-44] and the mechanisms of core metabolic processes [45, 46], biofilm production [47-51], capsule production [52] and resistance to oxidative stress have been elucidated $[53,54]$. Accidental passage through a laboratory worker also identified putative human host adaptations in vivo [55].

Since 1977 the NCTC 11168 strain has been an important part of efforts to better understand this pervasive pathogen. However, there are limitations to the use of type strains, the most obvious being that bacteria display considerable variation within species. For example, in C. jejuni, some strains cause a significant amount of disease in humans while others do not - owing, in part, to their inability to survive the passage from reservoir host through the food production chain to contaminate human food [56]. This kind of phenotypic variation among strains is well documented in many species and is a central reason for the growing emphasis on population genomics when trying to understand the ecology and evolution of bacteria [57]. A second, more inconspicuous limitation on the use of type strains shared among laboratories is that they might not all be the same. Strains are not sensu stricto clones and may display low levels of genetic variation. Clearly, when frozen there is little opportunity for genome evolution to occur [58]. However, whenever there is growth, for example in the process of subculturing isolates, there is an opportunity for genetic variability to be generated within the population. This may be important for interpreting research findings in different groups as even single SNPs can potentially have an impact on phenotype, for example in antimicrobial resistance [59] or host tropism [60]. The aim of the present study was to investigate if, over time, multiple passages under 


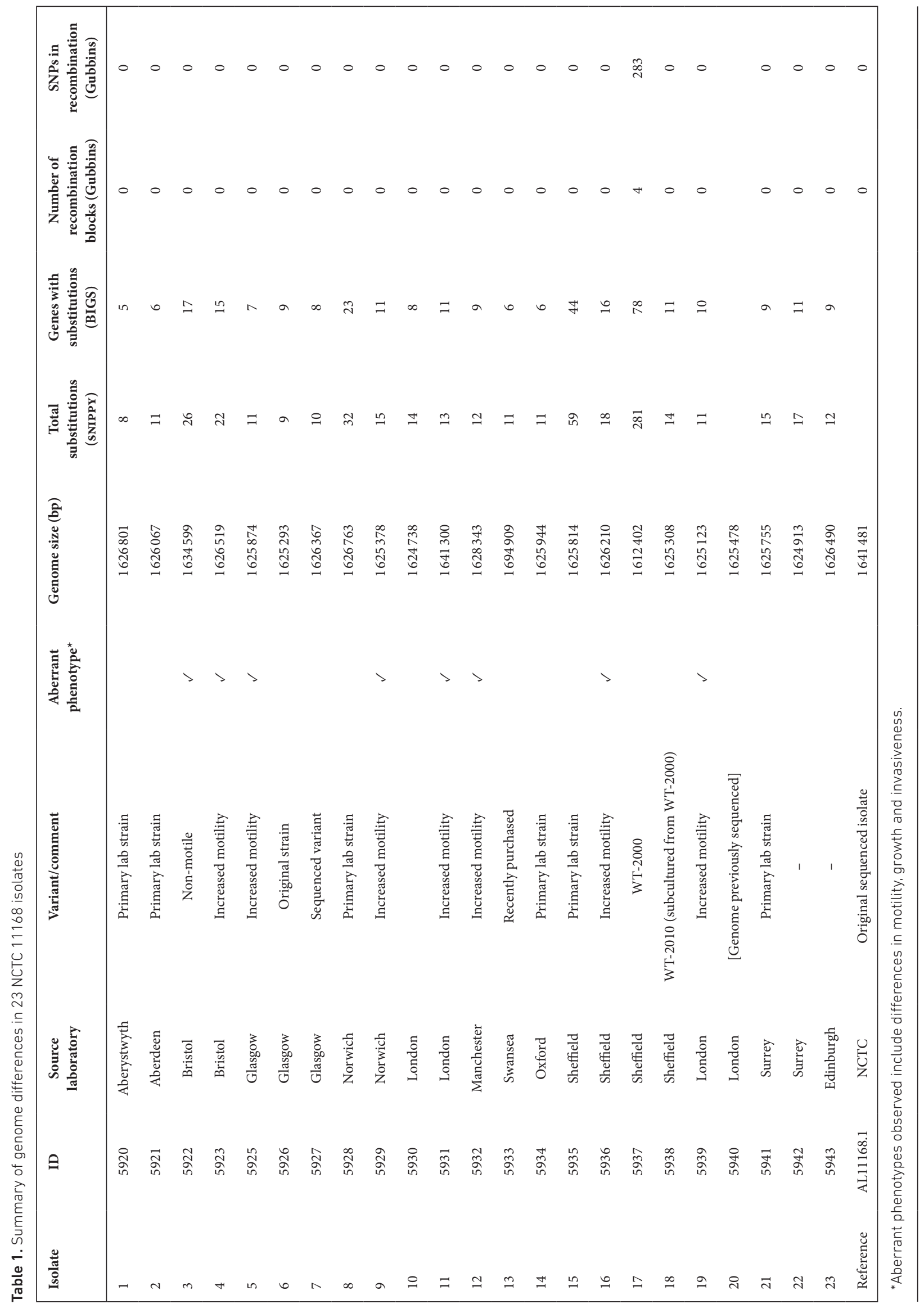




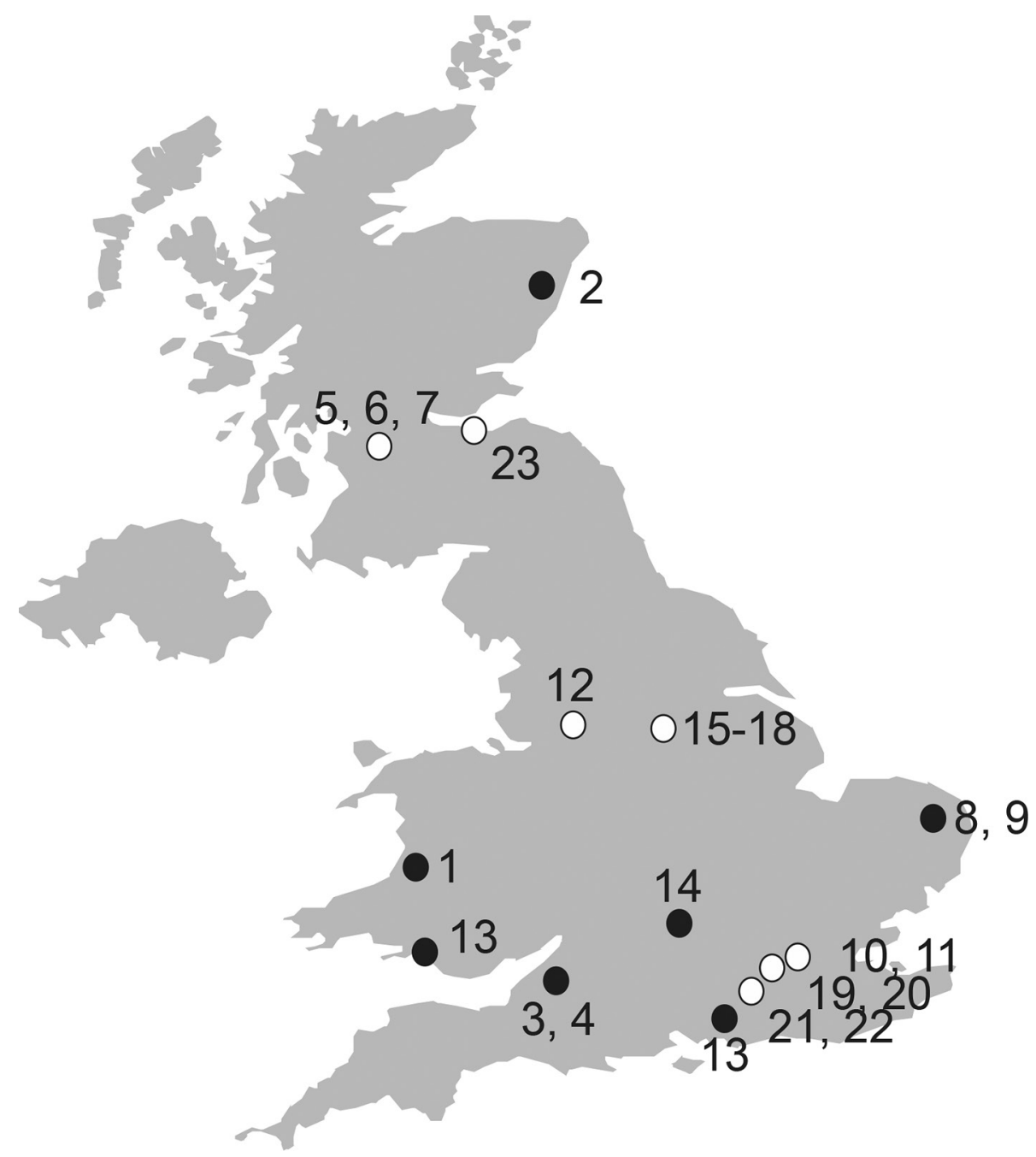

Fig. 1. The location of laboratories contributing C. jejuni NCTC 11168 isolates. The most recent NCTC 11168 isolate was obtained by Swansea (isolate 13) in 2016 from the NCTC collection. Other isolates obtained directly from the NCTC collection are coloured black, while isolates obtained via a second laboratory are coloured white.

potentially different growth conditions in different laboratories have introduced genotypic and phenotypic variation into a collection of NCTC 11168 C. jejuni.

\section{METHODS}

\section{Isolates and genome sequencing}

Twenty-three laboratory reference C. jejuni NCTC 11168 isolates from around the UK were collected and (re)sequenced. The year in which the laboratory received the isolate is noted along with its known heritage (Table 1). DNA was extracted using the QIAamp DNA Mini Kit (Qiagen), according to the manufacturer's instructions and quantified using a Nanodrop spectrophotometer. Genome sequencing was performed on an Illumina MiSeq sequencer using the Nextera XT Library Preparation Kit. Libraries were sequenced using a $2 \times 300$ bp paired end v3 reagent kit (Illumina). Short read pairedend data were trimmed using TRIMMOMATIC (version 0.35; paired-end mode) and assembled using the de novo assembly software, SPAdes (version 3.8.0; using the careful command). The average number of contigs in the resulting assemblies was 19.7 (range: 13-36) for an average total assembled sequence size of 1629408 bp (range: 1612402-1694909 bp). The average N50 contig length was 173674 bp (range: $100444-271714$ bp) (Table S1, available in the online version of this article).

\section{Population structure and phylogenies}

Sequence alignments and genome content comparison analyses using BLAST were performed gene-by-gene, as implemented in the BIGSdb platform $[61,62]$ as described in previous Campylobacter studies [63-66]. A gene was considered present in a given genome when its sequence aligned to an NCTC 11168 locus with more than $70 \%$ sequence identity over at least 50 $\%$ of sequence length using BLAST (File S1, available in the 
online version of this article) [67]. Genomes were aligned by concatenating single-gene alignments using MAFFT [68]. For context, collected NCTC 11168 isolates were augmented with 83 previously published genomes representing the known genetic diversity in C. jejuni (Table S2). Genes present in $90 \%$ or more of the isolate genomes were aligned (1 359883 bp; File S2) and a maximum-likelihood phylogeny was reconstructed in FastTree (version 2.1.10; with the generalized time reversible substitution model) [69]. A second alignment of just the collected NCTC 11168 strains was made (1555326 bp; File S3) to build an additional maximum-likelihood tree, which was used as input for ClonalFrame-ML to mask putative recombination sites (version 1.11-3) [70] and visualized in microreact: https://microreact.org/project/NCTC11168 [71].

\section{Estimating genome variation}

Sequence reads were compared to the completed NCTC 11168 reference genome (AL11168.1) using SNIPPY (version 3.2dev; File S4) [72] to estimate nucleotide differences between our laboratory reference isolates and the originally sequenced genome. Assembled genomes were annotated with PROKKA (version 1.13) [73] and the number of polymorphisms introduced by mutation and recombination was inferred using Gubbins (version 2.3.1) [71] for each isolate (per branch; File S5). All high-performance computation was performed on MRC CLIMB in a CONDA environment $[74,75]$.

\section{Phenotype testing}

Isolates were recovered from frozen storage on Columbia blood agar (E and O Labs) and incubated under microaerobic conditions at $37^{\circ} \mathrm{C}$ and subcultured in Mueller-Hinton broth (Oxoid) and grown microaerobically overnight at $37^{\circ} \mathrm{C}$.

\section{Bacterial growth assays}

Broth cultures were standardized to an $\mathrm{OD}_{600}$ of 0.05 . For growth curves at 37 and $42{ }^{\circ} \mathrm{C}, 20 \mu \mathrm{l}$ of the standardized broth culture was added to $180 \mu \mathrm{l}$ of Mueller-Hinton broth in a microtitre plate. Optical densities were measured at hourly intervals over a period of $48 \mathrm{~h}$ using an OMEGA FLUOstar (BMG LabTech) plate reader with an atmospheric environment of $10 \% \mathrm{CO}_{2}$ and $3 \% \mathrm{O}_{2}$. Growth curve assays were performed in triplicate, with three technical replicates for each biological replicate. Multiple comparisons among isolates at 37 and $42{ }^{\circ} \mathrm{C}$ were compared using a one-way ANOVA with a Tukey post-test [76].

\section{Swarming assays and motility}

For each isolate, a $1 \mathrm{ml}$ aliquot of the standardized preculture $\left(\mathrm{OD}_{600} 0.05\right)$ was transferred to $5 \mathrm{ml}$ of fresh Mueller-Hinton broth and $2 \mu \mathrm{l}$ was pipetted onto the centre of semi-solid Mueller-Hinton agar [11.5 g Muller Hinton broth, $2.5 \mathrm{~g}$ Agar 3 (Oxoid) in $500 \mathrm{ml}$ deionized water] and incubated at $42{ }^{\circ} \mathrm{C}$ for $24 \mathrm{~h}$. Variation in isolate swarming was observed on Mueller-Hinton motility plates. Motile isolates spread across the plates and halo diameters were measured after 1 day of incubation. Isolates were grouped into three categories: non-motile isolates did not spread across the plate; isolates with halo diameters up to $1.5 \mathrm{~cm}$ were categorized as motile; and those with halos of a diameter above $1.5 \mathrm{~cm}$ were designated as hyper-motile [36].

\section{Invasion assays}

A chicken gut epithelial cell line (MM-CHiC clone, 8E11; Micromol) and a human colon epithelial adenocarcinoma cell line (HT-29) were used to assay invasion of Campylobacter in vivo. A 24-well plate was seeded with $8 \mathrm{E} 11$ cells in assay medium [modified McCoy's 5A/DMEM/F-12 with L-glutamine $(5 \mathrm{mM})$ and supplemented with $5 \% \mathrm{FBS}$ ] and incubated at $37^{\circ} \mathrm{C}$ in $5 \% \mathrm{CO}_{2}$ for between 4 and 7 days. Liquid cultures were standardized by diluting with Mueller-Hinton broth to between 0.030 and 0.080 . Aliquots of $200 \mu \mathrm{l}$ from each isolate were deposited into a 96-well plate and diluted serially. The original stock and dilutions were spread onto Columbia horse blood agar and incubated for $24 \mathrm{~h}$ microaerobically at $42{ }^{\circ} \mathrm{C}$. Once the cells had reached confluent growth, the medium was removed and the monolayer was washed three times with warm PBS. An aliquot of $1 \mathrm{ml}$ pre-warmed antibiotic-free supplemented Dulbecco's modified Eagle medium (DMEM) was added to each well and inoculated with $100 \mu \mathrm{l}$ $1 \times 10^{7}$ c.f.u. Following incubation in $5 \% \mathrm{CO}_{2}$ at $37^{\circ} \mathrm{C}$ for $4 \mathrm{~h}$, the cells were washed twice with $2 \mathrm{ml}$ PBS supplemented with $4 \mu \mathrm{l}\left(100 \mu \mathrm{ml}^{-1}\right)$ gentamicin and incubated for a further 1.5 h. Cells were washed three times with PBS and an aliquot of $1 \mathrm{ml}$ of warmed TrypLE (Gibco) was added to each well and incubated at $37^{\circ} \mathrm{C}$ for $10 \mathrm{~min}$. The lysed monolayer solution was diluted serially and spread onto Columbia horse blood agar in duplicate. Plates were incubated overnight at $42^{\circ} \mathrm{C}$ in a microaerobic environment and enumerated pre- and postinvasion to calculate the percentage of invaded inoculum. Assays with human HT-29 cells were performed with McCoys growth media. Invasion assays were performed in triplicate and analysed using unpaired $t$-tests with Welch's correction.

\section{RESULTS AND DISCUSSION \\ Not all reference strains are equal}

Since its deposition at the NCTC there have been two main dissemination hubs of NCTC 11168 . Ten of the 23 isolates we collected were obtained by contributing laboratories directly from the NCTC collection, while 13 isolates had come via another laboratory (Fig. 1). DNA was extracted from each isolate and sequenced, and the genome was assembled (Table S1). All 23 isolates clustered closely in the host-generalist ST-21 lineage when compared on a maximum-likelihood phylogenetic tree (Fig. 2a). This suggests that despite some phenotypic heterogeneity, all isolates derived were from a recent common ancestor and no strains were misidentified during passage. Micro-evolutionary differences among closely related NCTC 11168 isolates were observed on a recombination-free phylogeny constructed using ClonalFrameML (Fig. 2b). Genomes were compared to the original NCTC 11168 genome and as many as 281 SNP differences were observed (up to 15 genes in isolate 17) among collected 


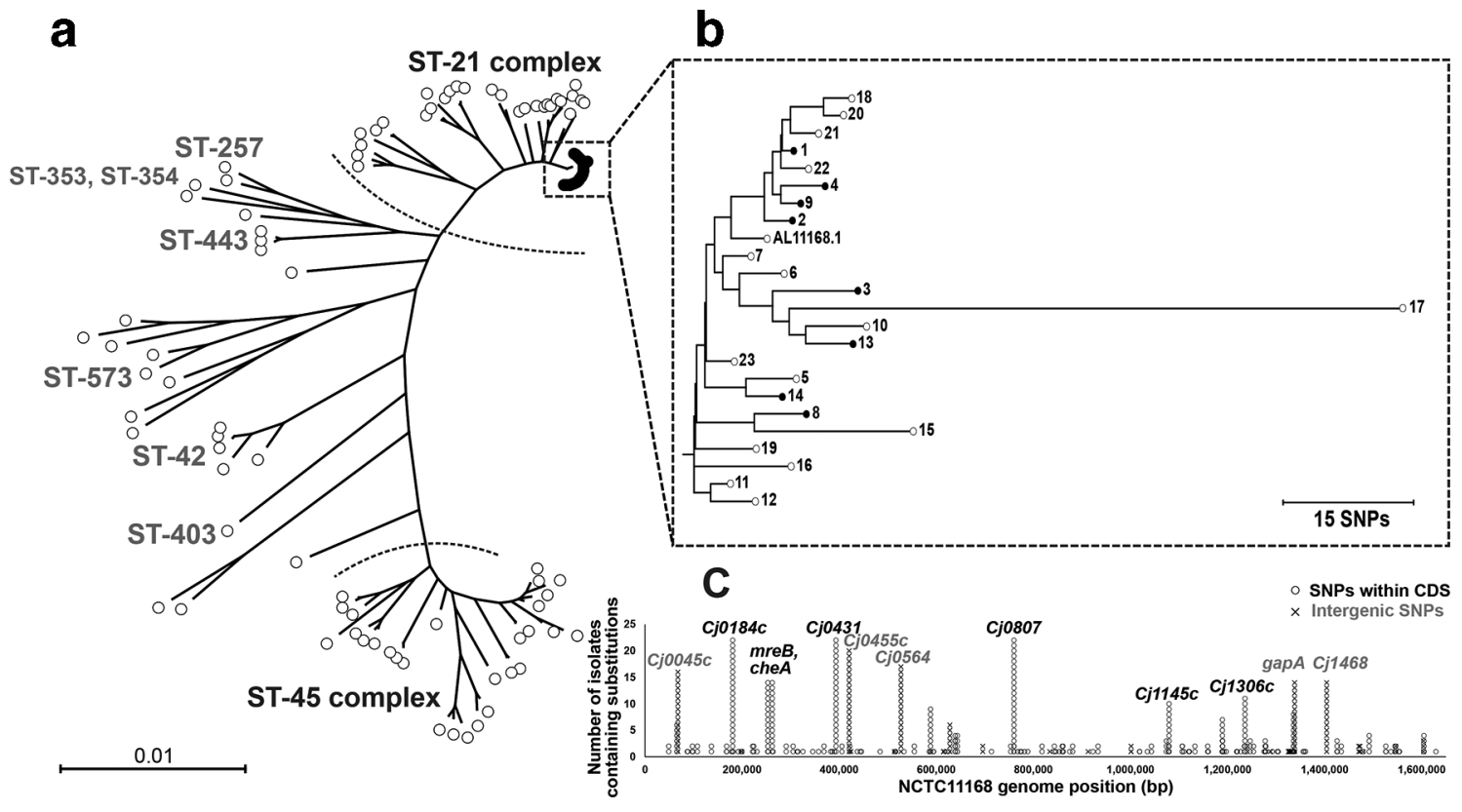

Fig. 2. Genetic variation among C. jejuni NCTC 11168 genomes. (a) NCTC 11168 isolates were contextualized with 83 previously published genomes representing the known genetic diversity in C. jejuni (total of 106 isolates). Genes present in $90 \%$ or more of the isolate genomes were aligned (1 $359883 \mathrm{bp}$ ) and a maximum-likelihood phylogeny was reconstructed in FastTree2 with the generalized time reversible substitution model. Bar, genetic distance of 0.01. (b) Recombination was masked using ClonalFrame-ML to produce an alignment of the NCTC 11168 isolates only ( $n=23 ; 1555326$ bp). Bar, 15 nt substitutions. (c) The position of all nucleotide substitutions identified using SNIPPY were mapped against the original NCTC 11168 genome (AL11168.1). SNPs found within coding regions (CDS) are represented with circles and SNPs located in intergenic regions are represented with an X. Gene names are given where variation was observed in 10 or more of the isolates.

laboratory strains and the reference (Fig. 2c; Table 1). However, in 21 of 23 isolates (91\%) there were 32 or fewer SNP differences compared to the reference (Table 1). There was an average of 29 SNP differences between the laboratory strains and the reference, and the fewest SNPs in any comparison was eight SNP differences (in five genes in isolate 1).

Under ideal storage conditions one might not expect to see any evidence of recent recombination in the laboratory reference strains. Nevertheless, we estimated the number of mutations and recombination events using Gubbins. In total, 436 of the 632 SNPs (69\%) we identified were found within protein coding regions, of which 83 were synonymous mutations (19\%; File S5). The only isolate where we inferred any recombination was isolate 17 , which has acquired four recombination blocks comprising a total of 14816 bp, incorporating 283 SNPs. In comparison, 29 SNPs were identified outside these recombination blocks (as a result of mutation), corresponding to a ratio at which recombination introduces nucleotide changes, relative to mutation $(\mathrm{r} / \mathrm{m})$ of 9.76 (File S5). This isolate also lost a block of 15 genes (Cj1319-1333; File S1), which includes a maf-family gene (maf3/Cj1334) involved in post-translational modification of flagellins. Also missing were the neuC2/Cj1328, neuB2/Cj1327, ptmA/Cj1332 and $\mathrm{ptmB} / \mathrm{Cj} 1331$ genes involved in the addition of pseuaminic/legionaminic acid to C. jejuni flagellins [32, 77, 78]. A knockout mutant of the final gene in this block, Cj1333, demonstrated compromised agglutination and reduced invasion (in INT-407 cells) [78]. This region of the C. jejuni genome is prone to recombination and has shown a high level of diversity and is often implicated in bacterial virulence [34, 35, 37, 79-82]. Isolate 17 was hyper-motile and also among the most invasive isolates when tested against chicken cell lines, but invaded human cell lines poorly (Table 2 ).

Isolate motility was tested in vitro [83] and phenotypic variation was observed among NCTC 11168 isolates (Table 2). Since its original dissemination, motile, non-motile and hyper-motile variants have been reported $[25,28,84]$. Despite previous observations describing increased motility, only three strains were categorized as hyper-motile in our assays (swarming $>1.5 \mathrm{~cm}$ ), all of which had been passed between at least two laboratories before entering our collection. Only $50 \%$ of the isolates received by laboratories directly from the NCTC collection were motile (Table 2). Changes in motility can be a result of differences in the flaA and flaB genes resulting in attenuated flagella assembly [36]. However, we did not identify any non-synonymous mutations within the flaA or flaB genes. A shared frameshift mutation was identified in two hyper-motile isolates (11 and 16) within the core motor protein, fliR [85-87]. Isolate motility is also influenced by phase-variable gene expression as a result of upstream homopolymeric repeat regions $[24,88,89]$. Three motility-associated genes (maf1/Cj1348, maf4/Cj1335 and 


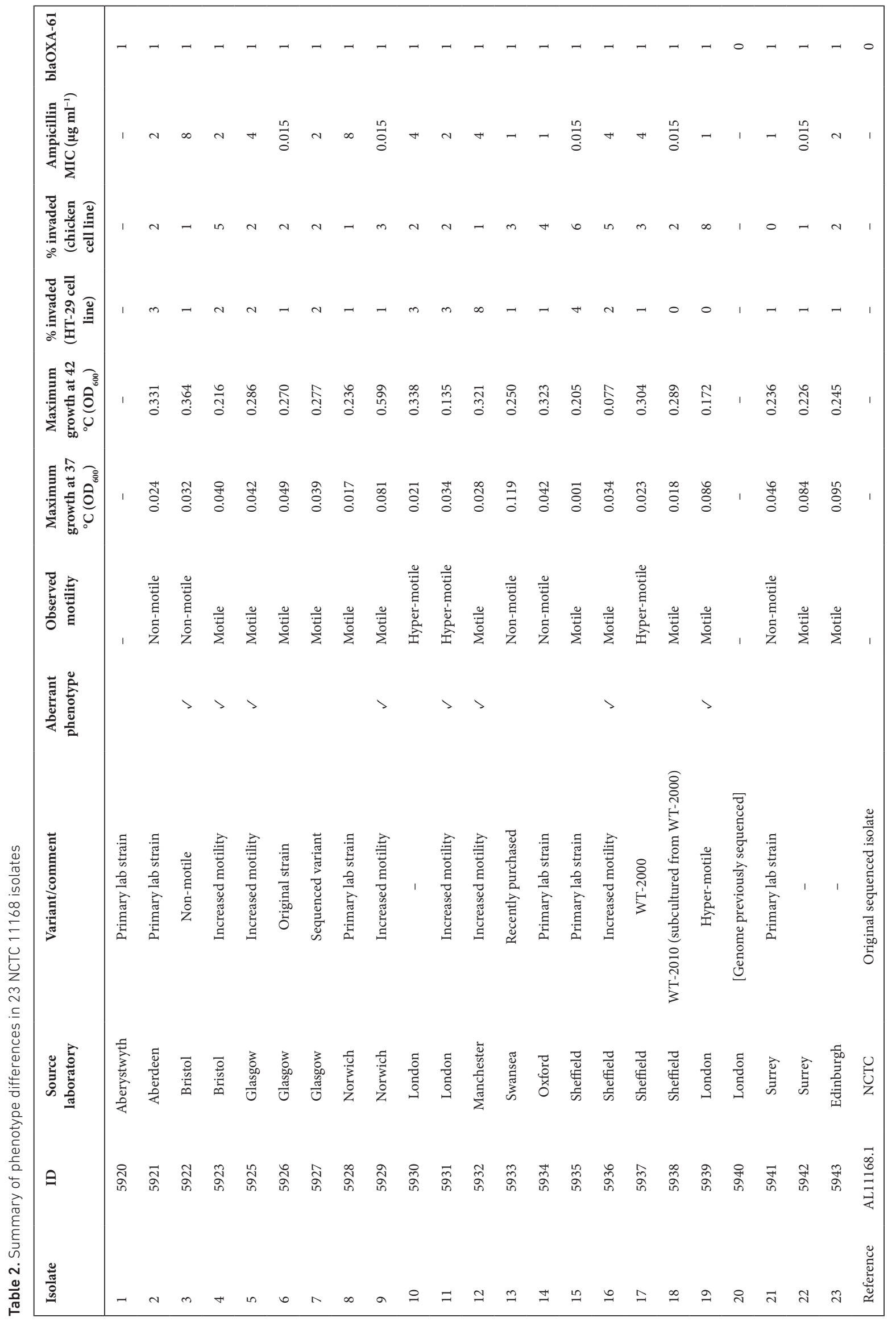


a

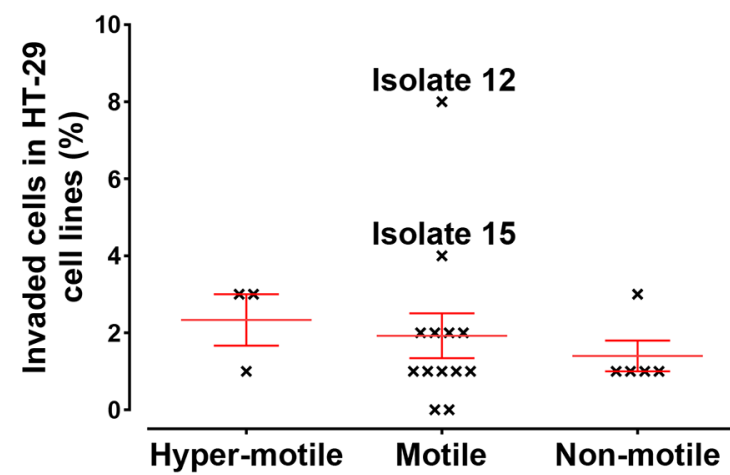

C

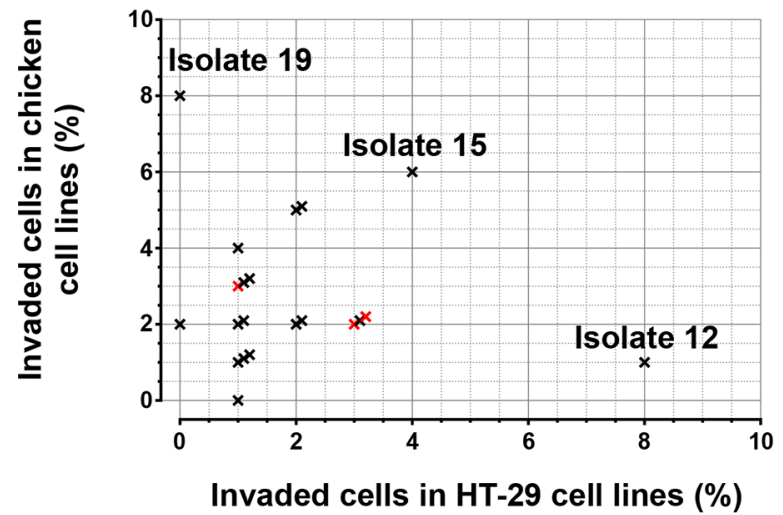

e

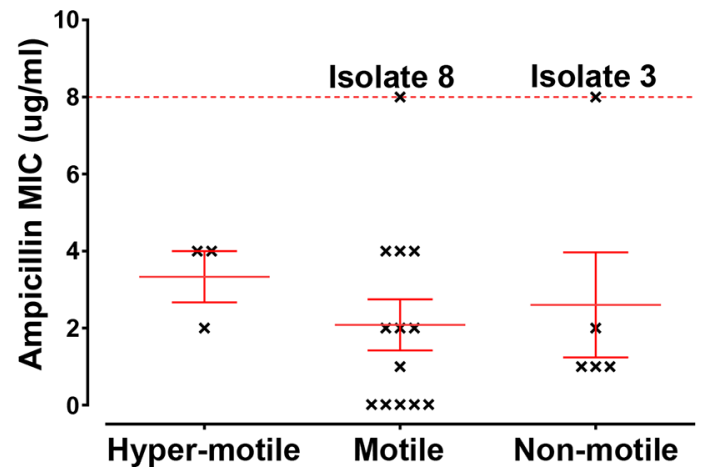

b

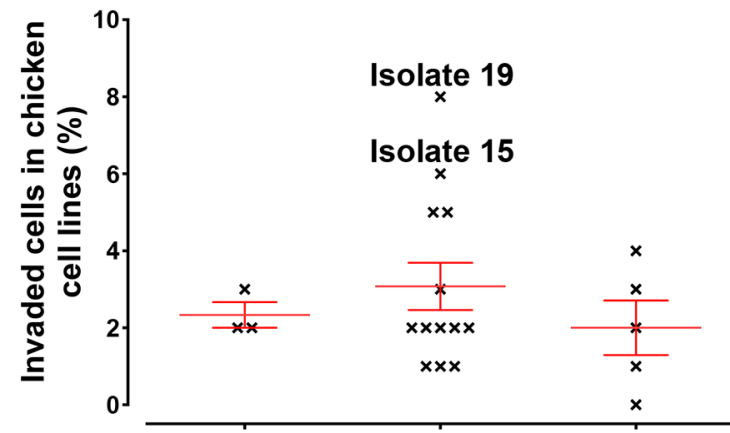

Hyper-motile Motile Non-motile

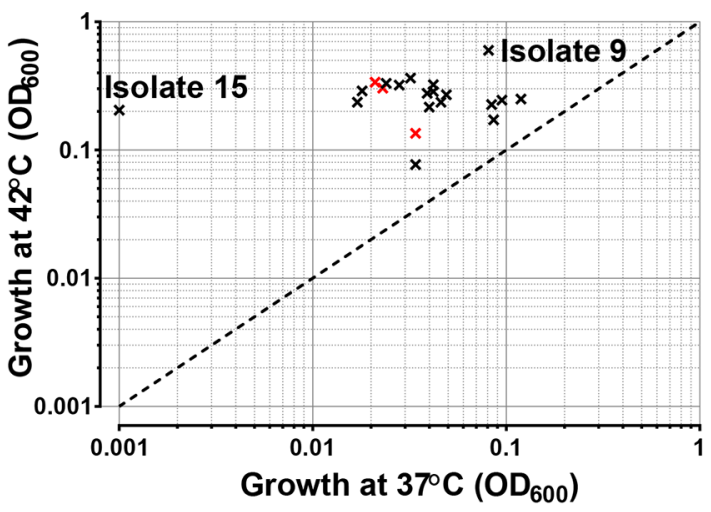

Fig. 3. Phenotypc variation among C. jejuni NCTC11168 genomes. Invasion assays were carried out for strains categorized by motility phenotypes in (a) human HT-29 and (b) chicken cell lines. For each isolate the percentage of invaded original inocula is plotted with a mean line and bars representing SEM. Comparisons were made between (c) invasiveness in these cell lines and (d) maximum growth at different temperatures, with hyper-motile isolates coloured red. The minimum inhibitory concentration (MIC) of ampicillin was determined for isolates grouped by motility (e). 
maf7/Cj1342c) were among 31 phase-variable regions recently identified in NCTC 11168 [90] and were among SNPs we identified in non-coding intergenic regions (196 of 632; $31 \%$; File S4). Twelve genes (Cj0045c, Cj0184, mreB, cheA, Cj0431, Cj0455c, Cj0564, Cj0807, Cj1145c, Cj1306c, gapA and Cj1468) contained nucleotide polymorphisms in 10 or more NCTC 11168 isolates, of which five have been shown to be subject to phase variation (Cj0045c, Cj0455c, Cj0564, gapA and Cj1468; Fig. 2c) [89]. Growth of motile bacteria in culture media can result in loss of motility as flagella construction is energetically expensive [91, 92]. In batch culture, rapid growth is prioritized and loss of flagella can be advantageous [93, 94].

Adequate flagella construction is an important virulence factor because, in addition to motility, flagella also contribute to invasion and secretion $[95,96]$, without which colonization is impaired [28]. The ability of isolates to invade human and chicken intestinal epithelial cell lines was tested in vitro by a gentamicin protection assay (Fig. 3a, b). Fourteen of 21 isolates tested invaded the 8E11 chicken cell line more effectively compared to the human HT-29 cell line (Fig. 3c). On average, motile ( $n=13,2$ and $3 \%$ of the original inoculum invaded chicken and human cell lines, respectively) and hyper-motile isolates ( $n=3 ; 2 \%$ of the original inoculum invaded chicken and human cell lines) invaded both cell lines in greater numbers than non-motile isolates $(n=5$; 1 and $2 \%$ of the original inoculum invaded chicken and human cell lines, respectively; Table 2; Fig. 3a, b). Several genes containing SNPs in multiple isolates have been shown previously to contribute to increased invasion and virulence, including mreB ( $n=14)$, cheA ( $n=14)$, Cj0431 $(n=22)$, Cj0455 $(n=20), \operatorname{Cj0807}(n=22)$ and $C j 1145(n=10)[55,81,97]$. Isolate growth was tested at 37 and $42{ }^{\circ} \mathrm{C}$, with all growing to a higher optical density at avian body temperature $\left(42^{\circ} \mathrm{C}\right)$ (Fig. $\left.3 \mathrm{~d}\right)$. Isolate 15 grew particularly poorly at $37^{\circ} \mathrm{C}$. We identified the OXA-61 gene in the majority of isolates, but only two were resistant to ampicillin, according to CLSI guidelines (isolates 3 and 8; Table 2; Fig. 3e) [98]. No SNP changes were observed in $c m e A B C$ genes in any isolate (File S1).

\section{The role of model strains in an age of population genomics}

In most cases (21 of 23 isolates; 91\%) we observed fewer than 32 SNPs between the laboratory isolate and the type strain deposited in the NCTC archive. However, even these minor changes are associated with observable phenotypic differences (motility and invasion as seen here). This could be seen as a challenge to the reproducibility of experiments in different laboratories that use ostensibly identical strains $[55,97]$. It is accepted among microbiologists that there is potential for variation among type strains that may display considerable genome plasticity, such as in Helicobacter pylori [99]. Consistent with this, variants of C. jejuni NCTC 11168 are defined as motile/non-motile, colonizer/non-colonizer for use in specific experiments.

Technical advances in high-throughput genome sequencing and analysis methods continue to improve understanding of $C$. jejuni from bottom-up studies that test the function of specific genes or operons, often with insertion or deletion mutants $[55,97]$, to top-down comparative genomic approaches in which isolates are clustered by phenotype and associated genomic variations are identified in large genome collections [50, 64, 100]. Early genome typing using DNA microarrays hinted at the level of diversity among $C$. jejuni isolates $[27,101]$, and comparisons of large isolate genome collections are now linking strain variation to differences in ecology [65, 102-105], epidemiology and evolution $[63,100,106-110]$. Advances in sequencing technology are helping us to study genome variation in greater depth, and long read sequencing of isolate 2 identified large inversions (>90 $000 \mathrm{bp}$ ) compared to the original finished genome (Table S1).

In conclusion, the genotypic and phenotypic differences among NCTC 11168 strains in this study, probably as a result of evolution during repeated passages, emphasizes the need for laboratories to maintain isolate collections with detailed records and good culture practices. This essentially reaffirms the work of microbiology pioneers who developed practices to minimize variation between strains and laboratories. However, in the genomics era, it may also be prudent to sequence strains more routinely, particularly as the costs continue to decline. While the interpretation of experiments using reference type strains may be adapting to more detailed genomic data and improved understanding of genome evolution, the strains themselves remain an essential resource in microbiology. The perceived power of large-scale comparative genomics and statistical genetics studies typically lies in the ability to identify genes or genetic variation that confers putative functional differences to the bacterium. Confirming these associated gene functions [56] requires traditional microbiology based upon a detailed understanding of reliable reference type control strains such as NCTC 11168.

\begin{abstract}
Funding information
B. P. and S. K. S. are supported by a Medical Research Council grant (MR/L015080/1). L. K. W. is funded by BBSRC (BB/M009610/1). The funders played no part in the study design, article preparation or the decision to publish.

Acknowledgements

All high-performance computing was performed on MRC CLIMB, funded by the Medical Research Council (MR/L015080/1). This publication made use of the PubMLST website (http://pubmlst.org/) developed by Keith Jolley and Martin Maiden (Jolley and Maiden, 2010) and sited at the University of Oxford. The development of that website was funded by the Wellcome Trust. We also thank all Campylobacter researchers who have maintained, cultured and disseminated this type strain since its deposition into the NCTC archives in 1977.
\end{abstract}

\section{Author contributions}

Conceptualization: S. K. S.; Formal analysis: B. P., L. K. W., J. K. C., M. D. H., M. D. and J. R.; Resources: S. S., B. S. L., C. C. -U., E. A., A. V., C. F., P. E., D. L., J. A. P., T. A. C., M. P. S., T. S. W., T. J. H., A. J. C., F. M. C., M. C. J. M., K. J. F., N. S., D. J. K., B. M. P., B. W. W., J. P. and A. H. M. vV.; Data curation: B. P., G. M., K. A. J., M. C. J. M. and S. K. S.; Writing: B. P., L. K. W. and S. K. S. All authors contributed to and approved the final manuscript.

Conflicts of interest

The authors declare that there are no conflicts of interest. 
Data bibliography

1. Pascoe B, Williams L. K., Calland J. K., Méric G, Hitchings M. D., Dyer M, Ryder J, Allen E, Vidal A, Fearnley C, Everest P, Linton D, Pachebat J. A., Cogan T. A., Stevens M. P., Wilkinson T. S., Humphrey T. J., Cody A. J., Colles F. M., Jolley K. A., Maiden M. C. J, Forbes K, Strachan N, Kelly D. J., Pearson B. M., Wren B. W., Parkhill J, van Vliet A. H. M., Sheppard S. K. Sequence Read Archive (SRA),BioProject Accession PRJNA517467 (2019).

2. Sheppard S. K., Didelot X, Jolley K. A., Darling A. E., Pascoe B, Méric G, Kelly D. J., Cody A. J., Colles F. M., Strachan N. J., Ogden I. D., Forbes K, French N. P., Carter P, Miller W. G., McCarthy N. D., Owen R, Litrup E, Egholm M, Affourtit J. P., Bentley S. D., Parkhill J, Maiden M. C. J., Falush D. Sequence Read Archive (SRA), BioProject Accession PRJNA177352 (2013).

3. Sheppard S. K., Didelot X, Méric G, Torralbo A, Jolley K. A., Kelly D. J., Bentley S. D., Maiden M. C. J., Parkhill J, Falush D. European Nucleotide Archive (ENA),Study Accession ERP000129 (2013).

4. Pearson B. M., Gaskin D. J., Segers R. P., Wells J. M., Nuijten P. J., van Vliet A. H. GenBank sequence: CP000814.1 (2007).

5. Fouts D, Nelson K, Sebastian Y. GenBank sequence: CP000538.1 (2006).

6. Fouts D. E., Mongodin E. F., Mandrell R. E., Miller W. G., Rasko D. A., Ravel J, Brinkac L. M., DeBoy R. T., Parker C. T., Daugherty S. C., Dodson R. J., Durkin A. S., Madupu R, Sullivan S. A., Shetty J. U., Ayodeji M. A., Shvartsbeyn A, Schatz M. C., Badger J. H., Fraser C. M., Nelson K. E. GenBank sequence: CP000025.1 (2004).

7. Gundogdu O, Bentley S. D., Holden M. T., Parkhill J, Dorrell N, Wren B. W. GenBank sequence: AL111168.1 (2006).

8. The University of Aberdeen. European nucleotide archive (ENA), BioProject accession PRJEB33069 (2019)

\section{References}

1. Méric G, Hitchings MD, Pascoe B, Sheppard SK. From Escherich to the Escherichia coli genome. Lancet Infect Dis 2016;16:634-636.

2. Skirrow MB. Campylobacter enteritis: a "new" disease. Br Med J 1977;2:9-11.

3. Kist M. [Who discovered Campylobacter jejuni/coli? A review of hitherto disregarded literature]. Zentralbl Bakteriol Mikrobiol Hyg A 1986;261:177-186.

4. Shulman ST, Friedmann HC, Sims RH. Theodor Escherich: the first pediatric infectious diseases physician? Clin Infect Dis 2007:45:1025-1029.

5. Dunne KA, Chaudhuri RR, Rossiter AE, Beriotto I, Browning DF et al. Sequencing a piece of history: complete genome sequence of the original Escherichia coli strain. Microb Genom 2017;3.

6. Altekruse SF, Swerdlow DL, Stern NJ. Microbial food borne pathogens. Campylobacter jejuni. Vet Clin North Am Food Anim Pract 1998;14:31-40.

7. Levy AJ. A gastro-enteritis cutbreak probably due to a bovine strain of vibrio. Yale J Biol Med 1946;18:243-258.

8. Jones FS, Orcutt M, Little RB. Vibrios (Vibrio Jejuni, n.sp.) associated with intestinal disorders of cows and calves. J Exp Med 1931;53:853-863.

9. Smith T, Taylor MS. Some morphological and biological characters of the spirilla (vibrio fetus, n. sp.) associated with disease of the fetal membranes in cattle. J Exp Med 1919:30:299-311.

10. Butzler JP. Campylobacter, from obscurity to celebrity. Clin Microbiol Infect 2004;10:868-876.

11. Dekeyser P, Gossuin-Detrain M, Butzler JP, Sternon J. Acute enteritis due to related vibrio: first positive stool cultures. J Infect Dis 1972;125:390-392.

12. Butzler JP, Dekeyser P, Detrain M, Dehaen F. Related vibrio in stools. J Pediatr 1973;82:493-495.

13. Cadranel S, Rodesch P, Butzler JP, Dekeyser P. Enteritis due to "related vibrio" in children. Am J Dis Child 1973;126:152-155.
14. Sebald M, Veron M. [Base dna content and classification of vibrios]. Ann Inst Pasteur 1963;105:897-910.

15. Veron M, Chatelain R. Taxonomic study of the genus campylobacter sebald and veron and designation of the neotype strain for the type species, Campylobacter fetus (Smith and Taylor) sebald and veron. Int J Syst Bacteriol 1973;23:122-134.

16. Skirrow MB, Benjamin J. Differentiation of enteropathogenic Campylobacter. J Clin Pathol 1980;33:1122.

17. Skirrow MB, Benjamin J. '1001' Campylobacters: cultural characteristics of intestinal campylobacters from man and animals. J Hyg 1980;85:427-442.

18. Woodward DL, Rodgers FG. Identification of Campylobacter heatstable and heat-labile antigens by combining the Penner and Lior serotyping schemes. J Clin Microbiol 2002;40:741-745.

19. Taylor DE, Chang N. Immunoblot and enzyme-linked immunosorbent assays of Campylobacter major outer-membrane protein and application to the differentiation of Campylobacter species. Mol Cell Probes 1987;1:261-274.

20. Lior H. New, extended biotyping scheme for Campylobacter jejuni, Campylobacter coli, and "Campylobacter laridis". J Clin Microbiol 1984:20:636-640.

21. Taylor DE, Eaton M, Yan W, Chang N. Genome maps of Campylobacter jejuni and Campylobacter coli. J Bacteriol 1992;174:2332-2337

22. Newnham E, Chang N, Taylor DE. Expanded genomic map of Campylobacter jejuni UA580 and localization of $23 \mathrm{~S}$ ribosomal rRNA genes by I- Ceul restriction endonuclease digestion. FEMS Microbiol Lett 1996;142:223-229.

23. Karlyshev AV, Henderson J, Ketley JM, Wren BW. An improved physical and genetic map of Campylobacter jejuni NCTC 11168 (UA580). Microbiology 1998;144:503-508.

24. Parkhill J, Wren BW, Mungall K, Ketley JM, Churcher C et al. The genome sequence of the food-borne pathogen Campylobacter jejuni reveals hypervariable sequences. Nature 2000;403:665-668.

25. Revez J, Schott T, Rossi M, Hänninen ML. Complete genome sequence of a variant of Campylobacter jejuni NCTC 11168. J Bacteriol 2012;194:6298-6299.

26. Gundogdu O, Bentley SD, Holden MT, Parkhill J, Dorrell N et al. Re-annotation and re-analysis of the Campylobacter jejuni NCTC11168 genome sequence. BMC Genomics 2007:8:162.

27. Dorrell N, Mangan JA, Laing KG, Hinds J, Linton D et al. Whole genome comparison of Campylobacter jejuni human isolates using a low-cost microarray reveals extensive genetic diversity. Genome Res 2001;11:1706-1715.

28. Gaynor EC, Cawthraw S, Manning G, MacKichan JK, Falkow S et al. The genome-sequenced variant of Campylobacter jejuni NCTC 11168 and the original clonal clinical isolate differ markedly in colonization, gene expression, and virulence-associated phenotypes. J Bacteriol 2004;186:503-517.

29. Cooper KK, Cooper MA, Zuccolo A, Joens LA. Re-sequencing of a virulent strain of Campylobacter jejuni NCTC11168 reveals potential virulence factors. Res Microbiol 2013;164:6-11.

30. Szymanski CM, Logan SM, Linton D, Wren BW. Campylobacter - a tale of two protein glycosylation systems. Trends Microbiol 2003;11:233-238.

31. Thibault $P$, Logan SM, Kelly JF, Brisson J-R, Ewing CP et al. Identification of the Carbohydrate Moieties and Glycosylation Motifs in Campylobacter jejuni Flagellin. J Biol Chem 2001;276:34862-34870.

32. Linton D, Karlyshev A V, Hitchen PG, Morris HR, Dell A et al. Multiple $\mathrm{N}$-acetyl neuraminic acid synthetase (neuB) genes in Campylobacter jejuni: identification and characterization of the gene involved in sialylation of lipo-oligosaccharide. Mol Microbiol 2000;35:1120-1134.

33. Guerry $P$, Ewing CP, Hickey TE, Prendergast MM, Moran AP. Sialylation of lipooligosaccharide cores affects immunogenicity 
and serum resistance of Campylobacter jejuni. Infect Immun 2000;68:6656-6662.

34. Howard SL, Jagannathan A, Soo EC, JPM H, Aubry AJ et al. Campylobacter jejuni glycosylation island important in cell charge, legionaminic acid biosynthesis, and colonization of chickens. Infect Immun 2009:77:2544-2556.

35. Linton D, Karlyshev AV, Wren BW. Deciphering Campylobacter jejuni cell surface interactions from the genome sequence. Curr Opin Microbiol 2001;4:35-40.

36. Jones MA, Marston KL, Woodall CA, Maskell DJ, Linton D et al. Adaptation of Campylobacter jejuni NCTC11168 to high-level colonization of the avian gastrointestinal tract. Infect Immun 2004;72:3769-3776.

37. Carrillo CD, Taboada E, Nash JHE, Lanthier P, Kelly J et al. Genome-wide expression analyses of Campylobacter jejuni NCTC11168 reveals coordinate regulation of motility and virulence by flhA. J Biol Chem 2004;279:20327-20338.

38. Perera VN, Nachamkin I, Ung H, Patterson JH, McConville MJ et al. Molecular mimicry in Campylobacter jejuni : role of the lipooligosaccharide core oligosaccharide in inducing anti-ganglioside antibodies. FEMS Immunol Med Microbiol 2007;50:27-36.

39. Holmes K, Mulholland F, Pearson BM, Pin C, McNicholl-Kennedy J et al. Campylobacter jejuni gene expression in response to iron limitation and the role of Fur. Microbiology 2005;151:243-257.

40. Palyada K, Threadgill D, Stintzi A. Iron acquisition and regulation in Campylobacter jejuni. J Bacteriol 2004;186:4714-4729.

41. Xu F, Zeng X, Haigh RD, Ketley JM, Lin J. Identification and characterization of a new ferric enterobactin receptor, CfrB, in Campylobacter. J Bacteriol 2010;192:4425-4435.

42. Nielsen LN, Luijkx TA, Vegge CS, Johnsen CK, Nuijten $P$ et al. Identification of immunogenic and virulence-associated Campylobacter jejuni proteins. Clin Vaccine Immunol 2012;19:113-119.

43. Mandal RK, Jiang T, Kwon YM. Essential genome of Campylobacter jejuni. BMC Genomics 2017;18:616.

44. de Vries SP, Gupta S, Baig A, Wright E, Wedley A et al. Genomewide fitness analyses of the foodborne pathogen Campylobacter jejuni in in vitro and in vivo models. Sci Rep 2017;7:1251.

45. Wright JA, Grant AJ, Hurd D, Harrison M, Guccione EJ et al. Metabolite and transcriptome analysis of Campylobacter jejuni in vitro growth reveals a stationary-phase physiological switch. Microbiology 2009;155:80-94.

46. Guccione EJ, Kendall JJ, Hitchcock A, Garg N, White MA et al. Transcriptome and proteome dynamics in chemostat culture reveal how Campylobacter jejuni modulates metabolism, stress responses and virulence factors upon changes in oxygen availability. Environ Microbiol 2017;19:4326-4348.

47. Kalmokoff M, Lanthier P, Tremblay T-L, Foss M, Lau PC et al. Proteomic analysis of Campylobacter jejuni 11168 biofilms reveals a role for the motility complex in biofilm formation. J Bacteriol 2006;188:4312-4320.

48. Reuter M, Mallett A, Pearson BM, van Vliet AHM. Biofilm formation by Campylobacter jejuni is increased under aerobic conditions. Appl Environ Microbiol 2010;76:2122-2128.

49. Brown HL, Hanman K, Reuter M, Betts RP, van Vliet AHM. Campylobacter jejuni biofilms contain extracellular DNA and are sensitive to DNase I treatment. Front Microbiol 2015;6:699.

50. Pascoe B, Méric G. Murray S, Yahara K, Mageiros L et al. Enhanced biofilm formation and multi-host transmission evolve from divergent genetic backgrounds in Campylobacter jejuni. Environ Microbiol 2015;17:4779-4789.

51. Oh E, Andrews KJ, Jeon B. Enhanced biofilm formation by ferrous and ferric iron through oxidative stress in Campylobacter jejuni. Front Microbiol 2018;9:1204.

52. Karlyshev AV, Linton D, Gregson NA, Lastovica AJ, Wren BW. Genetic and biochemical evidence of a Campylobacter jejuni capsular polysaccharide that accounts for Penner serotype specificity. Mol Microbiol 2000;35:529-541.
53. Atack JM, Kelly DJ. Oxidative stress in Campylobacter jejuni responses, resistance and regulation. Future Microbiol 2009;4:677-690.

54. Kendall JJ, Barrero-Tobon AM, Hendrixson DR, Kelly DJ. Hemerythrins in the microaerophilic bacterium $C$ ampylobacter jejuni help protect key iron-sulphur cluster enzymes from oxidative damage. Environ Microbiol 2014;16:1105-1121.

55. Thomas DK, Lone AG, Selinger LB, Taboada EN, Uwiera RR et al. Comparative variation within the genome of Campylobacter jejuni NCTC 11168 in human and murine hosts. PLoS One 2014:9:e88229.

56. Yahara K, Méric G, Taylor AJ, de Vries SPW, Murray S et al. Genome-wide association of functional traits linked with Campylobacter jejuni survival from farm to fork. Environ Microbiol 2017; 19:361-380

57. Sheppard SK, Guttman DS, Fitzgerald JR. Population genomics of bacterial host adaptation. Nat Rev Genet 2018;19:549-565.

58. Sleight SC, Orlic C, Schneider D, Lenski RE. Genetic basis of evolutionary adaptation by Escherichia coli to stressful cycles of freezing, thawing and growth. Genetics 2008;180:431-443.

59. Sproston EL, Wimalarathna HML, Sheppard SK. Trends in fluoroquinolone resistance in Campylobacter. Microb Genom 2018;4.

60. Viana D, Comos M, McAdam PR, Ward MJ, Selva L et al. A single natural nucleotide mutation alters bacterial pathogen host tropism. Nat Genet 2015:47:361-366.

61. Jolley KA, Maiden MCJ. BIGSdb: Scalable analysis of bacterial genome variation at the population level. BMC Bioinformatics 2010;11:595

62. Sheppard SK, Jolley KA, Maiden MCJ. A gene-by-gene approach to bacterial population genomics: whole genome MLST of Campylobacter. Genes 2012;3:261-277.

63. Sheppard SK, Didelot X, Jolley KA, Darling AE, Pascoe B et al. Progressive genome-wide introgression in agricultural Campylobacter coli. Mol Ecol 2013;22:1051-1064

64. Sheppard SK, Didelot X, Meric G, Torralbo A, Jolley KA et al. Genome-wide association study identifies vitamin B5 biosynthesis as a host specificity factor in Campylobacter. Proc Natl Acad Sci USA 2013;110:11923-11927.

65. Sheppard SK, Cheng L, Méric G, De Haan CPA, Llarena AK et al. Cryptic ecology among host generalist Campylobacter jejuni in domestic animals. Mol Ecol 2014.

66. Méric G, Yahara K, Mageiros L, Pascoe B, Maiden MCJ et al. A reference pan-genome approach to comparative bacterial genomics: identification of novel epidemiological markers in pathogenic Campylobacter. PLoS One 2014:9:e92798.

67. Altschul SF, Gish W, Miller W, Myers EW, Lipman DJ. Basic local alignment search tool. J Mol Biol 1990;215:403-410.

68. Katoh K, Standley DM. MAFFT multiple sequence alignment software version 7: improvements in performance and usability. Mol Biol Evol 2013;30:772-780

69. Price MN, Dehal PS, Arkin AP. FastTree 2 - approximately maximum-likelihood trees for large alignments. PLOS One 2010;5:e9490.

70. Didelot X, Wilson DJ. ClonalFrameML: efficient inference of recombination in whole bacterial genomes. PLoS Comput Biol 2015;11:e1004041.

71. Croucher NJ, Page AJ, Connor TR, Delaney AJ, Keane JA et al. Rapid phylogenetic analysis of large samples of recombinant bacterial whole genome sequences using Gubbins. Nucleic Acids Res 2015;43:e15-e15.

72. Seemann T. SNIPPY: Fast bacterial variant calling from NGS reads 2015 .

73. Seemann T. Prokka: rapid prokaryotic genome annotation. Bioinformatics 2014;30:2068-2069.

74. Grüning B, Dale R, Sjödin A, Chapman BA, Rowe J et al. Bioconda: sustainable and comprehensive software distribution for the life sciences. Nat Methods 2018;15:475-476. 
75. Connor TR, Loman NJ, Thompson S, Smith A, Southgate J et al. CLIMB (the cloud infrastructure for microbial bioinformatics): an online resource for the medical microbiology community. Microb Genom 2016;2.

76. Welch BL. On the comparison of several mean values: an alternative approach. Biometrika 1951;38:330.

77. Guerry P, Doig P, Alm RA, Burr DH, Kinsella N et al. Identification and characterization of genes required for post-translational modification of Campylobacter coli VC167 flagellin. Mol Microbiol 1996;19:369-378.

78. Golden NJ, Acheson DWK. Identification of motility and autoagglutination Campylobacter jejuni mutants by random transposon mutagenesis. Infect Immun 2002;70:1761-1771

79. Culebro A, Revez J, Pascoe B, Friedmann Y, Hitchings MD et al. Large sequence diversity within the biosynthesis locus and common biochemical features of Campylobacter coli lipooligosaccharides. J Bacteriol 2016;198:2829-2840.

80. Guerry P, Ewing CP, Schirm M, Lorenzo M, Kelly J et al. Changes in flagellin glycosylation affect Campylobacter autoagglutination and virulence. Mol Microbiol 2006;60:299-311

81. Wu Z, Periaswamy B, Sahin O, Yaeger M, Plummer P et al. Point mutations in the major outer membrane protein drive hypervirulence of a rapidly expanding clone of Campylobacter jejuni. Proc Natl Acad Sci 2016;113:10690-10695.

82. Parker CT, Gilbert M, Yuki N, Endtz HP, Mandrell RE. Characterization of lipooligosaccharide-biosynthetic loci of Campylobacter jejuni reveals new lipooligosaccharide classes: evidence of mosaic organizations. J Bacteriol 2008;190:5681-5689.

83. Backert S, Hofreuter D. Molecular methods to investigate adhesion, transmigration, invasion and intracellular survival of the foodborne pathogen Campylobacter jejuni. J Microbiol Methods 2013;95:8-23.

84. Karlyshev A V, Linton D, Gregson NA, Wren BW. A novel paralogous gene family involved in phase-variable flagellamediated motility in Campylobacter jejuni. Microbiology 2002;148:473-480.

85. Hendrixson DR, DiRita VJ. Transcription of sigma54-dependent but not sigma28-dependent flagellar genes in Campylobacter jejuni is associated with formation of the flagellar secretory apparatus. Mol Microbiol 2003;50:687-702.

86. Novik V, Hofreuter D, Galan JE. Identification of Campylobacter jejuni genes involved in its interaction with epithelial cells. Infect Immun 2010;78:3540-3553.

87. Reid AN, Pandey R, Palyada K, Naikare H, Stintzi A. Identification of Campylobacter jejuni genes involved in the response to acidic pH and stomach transit. Appl Environ Microbiol 2008;74:1583-1597.

88. Hitchen P, Brzostek J, Panico M, Butler JA, Morris HR et al. Modification of the Campylobacter jejuni flagellin glycan by the product of the Cj1295 homopolymeric-tract-containing gene. Microbiology 2010;156:1953-1962.

89. Aidley J, Rajopadhye S, Akinyemi NM, Lango-Scholey L, Bayliss CD et al. Nonselective bottlenecks control the divergence and diversification of phase-variable bacterial populations. MBio 2017:8

90. Aidley J, Wanford JJ, Green LR, Sheppard SK, Bayliss CD. Phasomelt: an 'omics' approach to cataloguing the potential breadth of phase variation in the genus Campylobacter. Microb Genom 2018:4.

91. Kearns DB. A field guide to bacterial swarming motility. Nat Rev Microbiol 2010;8:634-644.

92. Adler J, Templeton B. The effect of environmental conditions on the motility of Escherichia coli. J Gen Microbiol 1967;46:175-184.
93. Navarro Llorens JM, Tormo A, Martínez-García E. Stationary phase in gram-negative bacteria. FEMS Microbiol Rev 2010;34:476-495.

94. Rendueles 0 , Velicer GJ. Evolution by flight and fight: diverse mechanisms of adaptation by actively motile microbes. Isme $J$ 2016;11:555-568

95. Konkel ME, Klena JD, Rivera-Amill V, Monteville MR, Biswas D et al. Secretion of virulence proteins from Campylobacter jejuni is dependent on a functional flagellar export apparatus. J Bacteriol 2004:186:3296-3303

96. Guerry P. Campylobacter flagella: not just for motility. Trends Microbiol 2007:15:456-461

97. Revez J, Schott T, Llarena AK, Rossi M, Hänninen ML. Genetic heterogeneity of Campylobacter jejuni NCTC 11168 upon human infection. Infect Genet Evol 2013:16:305-309.

98. Clinical and Laboratory Standards. Performance Standards for Antimicrobial Susceptibility Testing An informational supplement for global application developed through the Clinical and Laboratory Standards Institute, CLSI Doc M100-S16. Wayne, PA: CLSI.

99. Draper JL, Hansen LM, Bernick DL, Abedrabbo S, Underwood JG et al. Fallacy of the Unique genome: sequence diversity within Single Helicobacter pylori Strains. MBio 2017;8.

100. Pascoe B, Méric G, Yahara K, Wimalarathna H, Murray S et al. Local genes for local bacteria: Evidence of allopatry in the genomes of transatlantic Campylobacter populations. Mol Ecol 2017:26:4497-4508.

101. Champion OL, Gaunt MW, Gundogdu O, Elmi A, Witney AA et al. Comparative phylogenomics of the food-borne pathogen Campylobacter jejuni reveals genetic markers predictive of infection source. Proc Natl Acad Sci USA 2005;102:16043-16048.

102. Sheppard SK, Dallas JF, Wilson DJ, Strachan NJC, McCarthy ND et al. Evolution of an agriculture-associated disease causing Campylobacter coli clade: evidence from national surveillance data in Scotland. PLoS One 2010;5:e15708.

103. Sheppard SK, Colles FM, McCarthy ND, Strachan NJC, Ogden ID et al. Niche segregation and genetic structure of Campylobacter jejuni populations from wild and agricultural host species. Mol Ecol 2011;20:3484-3490

104. Méric G, McNally A, Pessia A, Mourkas E, Pascoe B et al. Convergent Amino Acid Signatures in Polyphyletic Campylobacter jejuni subpopulations suggest human niche tropism. Genome Biol Evol 2018;10:763-774.

105. Woodcock DJ, Krusche P, Strachan NJC, Forbes KJ, Cohan FM et al. Genomic plasticity and rapid host switching can promote the evolution of generalism: a case study in the zoonotic pathogen Campylobacter. Sci Rep 2017;7.

106. Sheppard SK, McCarthy ND, Falush D, Maiden MCJ. Convergence of Campylobacter species: implications for bacterial evolution. Science 2008;320:237-239.

107. Sheppard SK, McCarthy ND, Jolley KA, Maiden MCJ. Introgression in the genus Campylobacter: generation and spread of mosaic alleles. Microbiology 2011;157:1066-1074.

108. Dearlove BL, Cody AJ, Pascoe B, Méric G, Wilson DJ et al. Rapid host switching in generalist Campylobacter strains erodes the signal for tracing human infections. Isme J 2016;10:721-729.

109. Baily JL, Méric G, Bayliss S, Foster G, Moss SE et al. Evidence of land-sea transfer of the zoonotic pathogen Campylobacter to a wild life marine sentinel species. Mol Ecol 2015;24:208-221 [Epub ahead of print Epub ahead of print].

110. Thépault A, Méric G, Rivoal K, Pascoe B, Mageiros L et al. Genomewide identification of host-segregating epidemiological markers for source attribution in Campylobacter jejuni. Appl Environ Microbiol 2017;83 